\title{
People and things in the ethnography of borders: materialising the division of Sarajevo
}

\author{
Stef Jansen \\ [Accepted for publication in Social Anthropology 21 (2013)]
}

\begin{abstract}
This article addresses the contrasting pull of two tendencies in anthropology: (a) calls to redress the purification of human from non-human actants and (b) calls to denaturalise notions of borders as things, foregrounding borderwork. The resulting dilemma-do we treat people and things as equivalent actants on a 'flat' plane or not?-is explored through an ethnographic exercise on the border that divides Sarajevo. This case study crystallises methodological possibilities, implications for critique and matters of accountability presented by either path. Ultimately, I argue, a focus on things is productive insofar as it functions within a focus on human practice.
\end{abstract}

KEY WORDS: borders, materiality, things, ethnography, Bosnia and Herzegovina

Framed within a set of current debates in anthropology, a focus on questions of the materiality of borders quickly leads the analyst to a fork in the road. One turn leads down the track taken by most anthropological studies of borders, while the other is the one favoured in much anthropological work on materiality. Schematically, the fork offers the following choices:

Most studies interested in the anthropology of borders seek to denaturalise the notion of borders as things, and especially as lines (Green 2009). They redirect the attention from borders-as-lines to borderwork, to the practices that produce, reproduce or modify degrees of borderness. Whether through bodily movement, military action, political negotiation, economic enterprise, the building of infrastructure or the cultivation of senses of belonging, it is people's engagement in borderwork that forms the core concern. The critical, potentially emancipatory dimension of such analyses lies in their redressing the taken-for-grantedness of borders-as-things, tracing their contingent production over time through social practices of reification. Charting reification, then, the anthropology of borders seeks to de-reify.

A number of approaches to materiality that enjoy considerable appeal in Britain today exhort us to take the other track. This includes work building on 'material culture' approaches (Miller 2006), Latour's actor network theory (2005a), Ingold's Heideggerian phenomenology (2000), Viveiros de Castro's ontologism (2003; Henare et al. 2007) and studies of affect drawing on Deleuze and Spinoza (e.g. Thrift 2009). For the purpose of argument-to crystallise their opposition to the emphasis on human practice in many border studies - I collectively refer to such diverging approaches as thingism. I focus on their shared call to dethrone people as the privileged locus of agency and to refrain from seeing things as merely objects that people (then conceived as subjects) use and represent in their practice. Crucially, thingism emphasises, in different vocabularies, that non-human 'actants' deserve equal analytical status: rather than approaching them as objects of practices that are seen as properly belonging to human sociality, it is argued, they are themselves part of a 
'flat' social that includes human and non-human entities. The critical, potentially emancipatory dimension of such analyses lies in their unmasking of the people/things distinction itself as the product of a modernist drive for culture/nature 'purification'. These authors consider this drive doomed to fail-and they aim to speed up its burial. Charting purification, then, thingism seeks to de-purify.

This article asks: if an ethnographic investigation of a border wishes to take seriously the role of both people and things, where does it turn at the fork? Before we take on this question through an ethnographic case study, let us establish if there really is a fork. Could we not find a reconciliatory third way, integrating both a thingist and a people-centred approach? Some anthropologists attempt to combine the two tracks. Yael Navaro-Yashin, for example, charts how, in Cyprus, people project affect onto ruins and how those things 'exude' affect (2009: 14), and Soumhya Venkatesan (2009) traces the agency of mats and that of their makers in South India. Both authors write in a predominantly thingist registeroften using the same verbs to denote the agency of people and of things-but ultimately refrain from collapsing people and things into one analytical category since 'the agency exercised by persons and things is not equivalent' (Ibid.: 92). Still, despite this analytical differentiation, they seek to de-reify at one point in the analysis and to de-purify at another. For these authors, either there is not really a fork, or there is but we can walk down both tracks.

In contrast, I argue that there is a fork and that it renders walking on the two tracks unfeasible. This is because thingism's key specificity is not simply a call to pay more attention to things, but a claim about agency that explicitly seeks to subvert the dualistanthropocentric core of people-centred approaches. For most thingists, it's either/or. While differences between the agency of things and that of people may become visible in our analysis, they argue, our conceptualisation of agency should not start from this; i.e. we should not 'impose a priori some spurious asymmetry among human intentional action and a material world of causal relations' (Latour 2005: 76). Rather than getting mired in nominalistic debates about the ontological status of 'agency', however, I suggest that, for ethnographic purposes, the defining disagreement at stake here is best rephrased as follows: should we start from an analytical distinction between human and non-human actants or not? If we start from this distinction, thingists will reject it as purification. If we do not make it, proponents of people-centred approaches will accuse us of reification. So while we can all agree on integrating both things and people into our analysis and find common ground in saying that things deserve more attention than many anthropologists have traditionally awarded them, no coherent conceptual framework can simultaneously postulate symmetry and asymmetry between agency of things and people. Making the distinction at some points and not at other points strikes me as an undesirable case of having our cake and eating it.

My ethnographic investigation of a border did therefore arrive at a fork in the road. As we shall see, it emerged predominantly as a methodological dilemma. Wishing to integrate both people and things in my research, should I approach gas pipes, shells or sausages-all of which will appear later-as actants on a 'flat' plane with people, or not? Should I attribute them the same analytical status, or not? This article explores this dilemma through an ethnographic exercise. 


\section{Beyond semiotics}

I invite you to join me on a thing-led walk through a street in Dobrinja, in the outskirts of Sarajevo, Bosnia and Herzegovina (BiH), where I conducted ethnographic research in 2008 and in 2010. This street runs from a main thoroughfare, flanked by a coach station and a school, to a square. With its loose tiles, parked cars and identical low-rise apartment buildings on both sides, it looks like many others in post-Yugoslav suburbs originally built in the 1980s and reconstructed after the 1990s wars. We see no fences, barriers, 'welcome' signs, or uniformed officers, ${ }^{1}$ yet we walk here on a deeply contested polity border, invested with considerable sovereignty claims, governmental logistics and affect. Which approach to people and things will provide the best ethnographic account of this border?

First, the easy way. The street is marked by two different street name signs. On the eastern side white Cyrillic letters on a blue background say 'Nikola Tešanović Street' and on the western side white Latin letters on a green background say 'Bosnian Assembly Square'. See those nametags on doorbells? They too display some regularity: on the east side we overwhelmingly find names that people in the post-Yugoslav states will identify as Serbian while on the west side most names will be identified as Bosniak. ${ }^{2}$ Turning eastwards onto the thoroughfare we notice relatively more Cyrillic script in shop windows than westwards. We haven't got all day, so I draw your attention to one product on sale only: pork sausages. There is clearly a broader range of them available on the eastern side.

And so on. As we walk, I 'read' the borderwork of some things in this Dobrinja street aloud to you, making certain differences noticeable and interpretable in a symbolic order in which they are mappable onto each other. The differences between the street name signs denote incorporation into two nationally marked polities. Nametags, imprecise guides, do reflect aggregate residential location of national groupings in which inhabitants would be classified, regardless of their self-identification. Since socioreligious heritage is the key criterion for differentiation between 'Christian' Serbs and 'Muslim' Bosniaks, many of whom do not eat pork, the relative difference in pork sausage sales represents another layer. So, as your resident semiotician, I embed selected things into patterns of signification governed by national difference. As I found repeatedly when receiving foreign visitors, explaining this border always requires some reference to this Serbian/Bosniak dichotomy.

Yet this semiotic exercise is far too easy. Like much symbolic anthropology, especially structuralist work, it lacks a practical dimension, and it is misleadingly a-temporal, systemcentric and binary-reproducing. It sucks everything into a master difference: east is Serbian, west is Bosniak. In fact, a closer look teaches us that there is considerable blurring. Latin script is used alongside Cyrillic to the east. Some names on doorbell tags cannot be unambiguously identified in national terms, and, anyway, they may not reflect actual inhabitants. Our street clearly demarcates an area inhabited by a large majority of people who would be classified-by name-as Bosniaks, from an area inhabited almost exclusively by people who would be classified-by name-as Serbs. Yet some would be classified as Croats or others, and, anyway, many inhabitants to the west self-identify as Bosnians, not as Bosniaks. Pork sales aren't that simple either: a butcher's immediately to the west offers a fine selection. Even unambiguous markers-such as nationalist posters, graffiti or books in stalls-are not concentrated on precisely aligned co-ordinates. A semiotic 'reading', reproducing a taxonomic focus on a taken-for-granted national difference and treating the border as a line that marks taken-for-granted national units, is unsatisfactory as a description and void of critical potential. 
Of course, any ethnographic analysis must dispel, as I did, notions of a neat line, but we should not be content with the classic trick of setting up a dichotomy in order to blur it immediately. Ethnography offers much more, both descriptively and critically, when investigating human practice beyond signification, and things beyond their meaning in a symbolic order. Moreover, the fact that this border is not neat does not mean it does not work as a border at all. The interesting anthropological question is how, when, to whom and to what degree certain things materialise as a border over time (cf. Green 2009; Massey 2005). Foregrounding questions of temporality, I now first propose a genealogy of our border and then I investigate how it is continuously materialised through regularities in bodily movement. Taking in people and things throughout, I assess the relative descriptive and critical value of a de-reifying people-centred methodology vs. a de-purifying thingist one.

\section{Outline of a genealogy of a border}

Key fact: never before 1992 has there been a border where we walk now, nor did the entities it demarcates exist. The 1991 census did not yield a majority of any nationality amongst Dobrinja's 30,000+ population, nor any residential segregation. Constructed in the 1980s, our street lay just inside the Sarajevo agglomeration-a little further east Dobrinja gave way to fields, a village, Yugoslav Army barracks and some industry. With our methodological dilemma in mind, let us now explore how human and non-human actants featured in the processes that made it a border from 1992 onwards.

As we sit down in a café on the thoroughfare, I point to the hill on which artillery was set up in Spring 1992. Our street was soon cut off from the city by a siege line, a dangerous space between two sets of barricades, traversed by bullets, shells and sometimes fleeing persons. Leaders of the newly proclaimed Republika Srpska (RS) ${ }^{3}$ aimed to segregate Dobrinja Serbs from others, encouraging them to move to suburbs controlled by 'their' army, as it closed the siege around Sarajevo. My interviews with stayees and escapees contained competing narratives of such movement. Did they leave pre-emptively, believing to be safer with their 'own'? Did they, like many others, flee siege conditions? Did they escape mistreatment as people suspected of disloyalty to BiH? We can't go into these questions here, but I mention them because they remain crucial to any account of that period. Also in 1992, non-Serbs were expelled from or fled areas held by the Army of RS. During the entire war our street was controlled by the latter, and west from our cafe we can see the now inconspicuous area where the siege line used to be. See the school across the road, now reconstructed? It was utterly devastated. That orthodox church? At the time its tower, still in construction, functioned as a sniper's nest, as did the buildings across, controlled, like most of Dobrinja and of the city, by the Army of the Republic of BiH.

In 1995 peace negotiations in Dayton (USA) ended military violence, establishing a sovereign $\mathrm{BiH}$ consisting of two largely nationally homogenised 'Entities': Republika Srpska and the 'Federation of BiH'. To fix the co-ordinates of the border between them, known as the Inter-Entity Boundary Line (IEBL), negotiators used a flight simulator. The IEBL largely followed military positions of the time but most Sarajevo suburbs held by the Army of RS were to be 'reintegrated' into Sarajevo and, thus, into the Federation. This occurred in Spring 1996. Yet our particular area of Dobrinja was an exception: due to the scale of the mapping equipment, the IEBL was not precisely topographically fixed here. The mined, 
barricaded space of the former siege line, between ruined buildings, did turn into a de facto border, with checkpoints manned by local and foreign officers. Our street, just to the east, thus remained effectively under RS control.

The precise co-ordinates of the IEBL in Dobrinja were contested until 2001, when arbitration fixed them just east of the former siege line, in the middle of our street. This paved the way for workers of the municipalities of 'East Sarajevo' and of 'New Town Sarajevo' to officially mark our street as a border by putting up the two signs. Here, RS, of which 'East Sarajevo' is a part, and the Federation, and, within it, Canton Sarajevo, of which 'New Town Sarajevo' is a part, meet. Current differences in nametags were thereby also stabilised. From 1992, when its non-Serbian residents were expelled, until 2001 arbitration, both sides of our RS-controlled street almost exclusively housed Serbs, some themselves displaced. ${ }^{4}$ After arbitration, some non-Serbs returned to their flats on the west side, now allocated to the Federation.

Meanwhile, in response to consecutive flows of Serbs into RS (before and during the 1992-1995 war, after 1996 reintegration, and after 2001 arbitration), a new settlement was being built near our street. East from our café we see new apartment blocks, cranes, mud and concrete mixers. Already in 1992 the RS leadership had announced plans for a 'Serbian Sarajevo', consisting of the parts of the city under its control. This RS capital would form a counterpoint to what they called, and often still call, 'Muslim Sarajevo'. 'Serbian Sarajevo' never became a thriving capital-partly due to a power shift in RS to the north-but this settlement retains explicit claims to separate city-hood. Beyond the furthest outlying 1980s buildings of Dobrinja, fixed by arbitration in RS, construction is ongoing and by 2008 at least 10,000 people ${ }^{5}$ lived in what was renamed into the 'City of East Sarajevo' after a 2004 decision of the BiH Constitutional Court.

The political legitimacy of our border is thus deeply contested. Its very existence is the result of the one-sided establishment of East Sarajevo (and all of RS) as a separate Serbian polity. Reflecting this, in interviews most East Sarajevans represented the IEBL as a legitimate achievement and the entity structure of $\mathrm{BiH}$ as the maximum possible degree of self-determination for $\mathrm{BiH}$ Serbs in the current geopolitical moment. The border, they argued, had to be established in a defensive war that territorialised national sovereignty to protect 'the Serbs' from 'the Muslims' (in this area). In contrast, most people in 'Federal' Dobrinja-including many Serbs-considered the IEBL an unfortunate consequence of a defensive war imposed on $\mathrm{BiH}$ patriots by a powerful Serbian nationalist army. ${ }^{6}$ Far from an achievement, it was then represented as the price paid for the end of military violence, an unfair reward for those who committed numerous crimes in their fight against $\mathrm{BiH}$ statehood.

Let me sum up this brief genealogy. Our street materialised as a border through the interplay of human and non-human actants on different scales: through the fighting, fleeing, expelling, negotiating, drawing practices of people and through the particular material characteristics of shells, sniper nests, mines, barricades, ruins, maps, even a flight simulator. As thingism reminds us, any change in any of those actants would have made some difference to the materialisation of this border. To understand the role of barricades we must consider the materiality of buses. To understand how people reoriented their daily movements we must consider the trajectories of shells (dependent, in part, on their material specifications). To understand the imprecise topography of IEBL drawings we must consider the scale used by flight simulator and mapping software. Clearly then, a genealogy of this border must incorporate both people and things. Moreover, much of our account can 
leave aside question of human intentions: once the barricade was up, once the shell approached the building, their materiality clearly produced dramatic performative effects regardless of such intentions. Yet does that imply that our account would gain from treating things and people as actants of the same order, as thingism exhorts us to do?

\section{A genealogy through things short of a thingist genealogy}

This Sarajevo border could not have been made without things, and the availability of certain things made certain forms of borderwork feasible. Focusing on things was thus methodologically useful for our genealogical account. Yet clearly a border could have been made without those precise things, using other ones instead. Without human practices of borderwork, on the other hand, no border would have existed at all, just as it did not exist at any point in time until 1992. The border's genesis in the 1992-1995 war, its 1996 shift after the Dayton Agreement, and its 2001 fixing by arbitration all resulted in displacement and reconfigured regularities in bodily movement. These collective and individual movements materialised the border. Things did not change overnight, but every time people reallocated them politically, residents started acting differently around them overnight, and thereby remade a border. People changed, things remained the same, and the border changed. Ultimately, then, in the making of our border, things were subordinated to human practices, not the other way around.

Since those practices revolved around things, a genealogy must incorporate things as well as people, but our account of the genesis of this Dobrinja border would not gain anything from a thingist insistence on the equivalence of their agency. Starting from a refusal to 'a priori impose' an asymmetry between human and non-human actants, we would still arrive at a genealogy in which, ultimately, the role of things in making this border turned out to be of a different order than that of people. In this concrete empirical case, a posteriori, their agency turned out to be asymmetrical anyway. While methodologically working through things, my genealogy privileged the charting of the reification of this border-foregrounding human practices that mobilised and fixed certain things-over seeking to uncover any equivalent agency those things themselves may have had. Statements that things and people are equivalent actants on a 'flat' plane would not make any significant contribution to our account, but my genealogy benefited from acknowledging the asymmetry between human and non-human actants from the start. Importantly, while thingists-and many of their critics-seek to locate the debate in the domain of the role awarded to human intentions, my asymmetrical conceptualisation of human and non-human agency is grounded instead in concerns with accountability. Let me elaborate on this with regard to the interrelated issues of descriptive accuracy and critical potential.

Like most anthropological studies of borders, my genealogy stopped short of taking the thingist track because my account would be misleading if it said only that street signs 'appeared', barricades 'emerged' or shells 'fell', and stopped at that. This would obscure the ultimate decisiveness for border-making of the human practices that constructed and fired them. Shells may not always fall where intended and their materiality is crucial, but without being fired they don't fall in the first place. Both people and things played a role in the becoming of this border, but it was not shaped in the same way by things as it was by people. My description chose to emphasise this and, importantly, my choice builds on emic 
de-reifications. Many residents themselves also emphasised the contingency of this border's existence, and all of them saw its topographical fixing in specific things in those terms. Even those strongly committed to its legitimacy, like many residents of East Sarajevo, recognised that it projected arbitrary claims of sovereignty onto certain things, not others. Legitimising stories of Serbian Bones and Serbian Lands functioned on a generic level in $\mathrm{BiH}$, but not even the most ardent supporter of Serbian nationalism living here claimed that the sides of our Dobrinja street-1980s buildings, pavements-were somehow nationally-ontologically different things with agency equivalent to that of human actants. 'East Sarajevo' had been purposefully produced as exclusively Serbian, and the fact that current residential patterns (and, as we shall see, bodily movement) largely reflected this was recognised as a result of contingent human practice. While few were fully satisfied with it, all alternatives were known to be equally contingent and human. Regardless of their political stance, then, residents emphasised that, ultimately, the border as it is today was drawn by people over things. Most people coded this human practice of 'drawing' as 'politics', dispelling the frequent thingist mistake that equates de-reification with voluntarism. Emphasising human practices of reification does not imply stating that people reify at will, or that all reify equally. On the contrary, since people, unlike things, can be held accountable, it poses questions of relative responsibility amongst the multitude of human agents involved in the production of this border through war- and war-related practices. This leads to the issue of critique.

Fierce disputes existed on (non-)accountability for war-time events in $\mathrm{BiH}$. But in terms of the ultimate post-war fixing of the IEBL in our street, we can be unusually precise. It was done by a man called Diarmuid Sheridan, who conducted the 2001 arbitration. Based on consultations with current and former residents, and on legal representations by various authorities, this decision process involved plenty of things. Yet it was purposefully removed from the things it demarcated. Sheridan's decision neither simply followed things (e.g. allocating the entire 1980s Dobrinja suburb to one side, or following geology, or legalising the siege line), nor did it straightforwardly privilege one of the two sovereignty claims. Leaving some but not all of the RS-controlled 1980s Dobrinja buildings, including the east side of our street, in RS, showed that arbitration was arbitrary. This is precisely why the Office of the High Representative (the supreme agency of the Foreign Intervention in $\mathrm{BiH}$ ) appointed a foreign judge. What was seen as legitimate (and ultimately arbitrary and reversible) human practice thus trumped the shape of things. And that shape of things, it was thereby emphasised, was itself in large part the product of what was judged illegitimate war-time human practice (now also conceived of as arbitrary and reversible). Arbitration thus purified the role of non-human from human actants-refusing to take the 'situation on the ground,' as embodied in things, for granted.

In response to this de-reification in emic understandings and in foreign intervention policies, I could have opted for a de-purifying genealogy of our border, showing how nonhuman actants (shells, barricades, minefields, ruins) conditioned human practices. And of course it would be ludicrous to deny that they did. With its relentless efforts to uncover the role of non-human actants, thingism usefully reminds us that any tracing of the making of this border must consider the materiality of things. The flight simulator is almost embarrassing in its perfection for an actor network interpretation. Yet note, again, that the entire spatial-logistic set-up of the Dayton negotiations was purposefully engineered by US government representative Holbrooke, a trained architect (C-lab n.d). Both the flight simulator and Holbrooke were actants, but my account would not gain any descriptive 
traction from conceiving of them in the same analytical order. Nor would a thingist refusal to analytically distinguish between the agency of human and non-human actants increase the critical potential of my ethnographic account. For our border, this potential revolves around elucidating its contingency, and thus raising questions of accountability. In fact, as many have pointed out, such issues tend to be obscured when we treat the agency of people and things on the same analytical plane. Existing de-reifications of our border in the genealogical accounts of residents and a foreign judge should thus not, in my view, be undone by privileging the alternative critical de-purifying potential of thingism.

\section{Things and affect in movement away from the border}

Let us finish our coffee and move on from genealogy to an analysis of our border's reproduction through people's comings and goings. Here we deploy the temporal focus, already present in my genealogy, both backwards and forwards. We also address the intersection of borderwork on different scales, sometimes involving contradictory tendencies. Camp out with me where our street joins the main Dobrinja thoroughfare. To the east, we see coaches at the East Sarajevo coach station. To the west, buses and trolleybuses fill up at a terminus of the Sarajevo city transport company. All vehicles in the west, and most in the east leave in the direction away from the border. ${ }^{7}$ No city transport passes us. We also notice the paucity of pedestrians passing our street compared to those moving away from it in either direction. Many people, clearly, do not cross this border. How should we understand this?

Given the violent making of this border, war-related affect would seem a likely source of explanation. The border hardened in part through regularities of war-time displacement in search of security, and post-war crossing could thus evoke fear. One might be spotted by pre-war acquaintances as someone living in the other entity. Moreover, the war left devastated buildings, a lack of greenery, shell marks and other material traces all over Sarajevo. Here too, thingism would give equivalent analytical status to non-human and human actants, tracing how things induce affect as much as how people project affect onto things (Thrift 2009). Sarajevo certainly houses innumerable things that, in a thingist approach, could be seen as war-related affect-inducers.

Through observation of regularities in bodily movement and through interviews, I first explored whether those who crossed experienced this as crossing at all, and whether those who did not cross felt they were not crossing something. ${ }^{8}$ Reflecting on their movements across the Dobrinja border, most people signalled that they did experience an acute sense that they were crossing a border in those instances. (Non-)crossings were thus affective events that materialised the border. Yet for many people bodily movement across the IEBL, or the thought of it, evoked less fear than a sense of unease due to an imposed crystallisation of one's nationality through confrontations with things on the other side. Explicitly national things-flags, street name signs, billboards, churches or mosques, etcwere particularly important here, but less obviously national things that residents were oblivious to, also featured. Unease was often mixed with indignation at the prominence of such things, which was then transposed collectively onto the residents, of whose values and desires they were seen to be an expression. In that way, many people from the west of our border argued along the lines of 'Why would I go to East Sarajevo? They shot at me for four years, and now look at those billboards, look how they commemorate that they, like, 
defended themselves. And towards us they act as if nothing happened'. Many people from East Sarajevo felt unwelcome in Sarajevo due to what they saw as unfair depictions of the war in BiH: 'Look at all those mosques! They made Sarajevo into a Muslim city and they act as if they were the only victims, as if we did not suffer at their hands'.

For some, then, (expected) confrontations with certain things evoked unease due to one's 'incompatibility' with them as a self-identified national other (e.g. 'When I am there I feel as if it's written on my forehead that I am a Serb'), whereas others resented the very experience of becoming nationalised themselves (e.g. 'There I really feel like I am a Bosniak'). People's concrete war-time experience on either side of the siege line was decisive here, not their nationality per se. Some people in 'Federal' Dobrinja were reluctant to enter East Sarajevo-from where they had been shelled-but did venture into other places in RS or Serbia. Yet war-related affect associated with things was not equally prevalent for everyone, nor was it necessarily an obstacle to cross. And other things, on either side of the border, also played a role in the affective structuring of movement: some men, for example, avoided any mountains or forests because they reminded them of their war-time engagements as soldiers. I thus found that some potential affect-inducing things were avoided or approached with greater apprehension than others, and that the border was not always a key factor in these patterns.

Like in its making, things are thus crucial in the reproduction of the border too. How then can we best grasp the relation between things and affect here? Take this example: after the war, many people from 'Federal' Dobrinja never visited Trebević, a mountain that previously served as a favourite excursion site. They usually explained this with reference to its war-time function as a base for shelling the city. The materiality of the mountain, thingists might say, induced affect. But many of those same people did not express the same reluctance to go to 'reintegrated' parts of Sarajevo such as Grbavica, from where they had also been besieged, and which is associated with great suffering. We could thus expect it to emanate similar or greater traumatic affect as Trebević. Shortly after the war, I was told, many avoided Grbavica, but during my 2008-2010 research, many people from Dobrinja passed through it daily. Overruling the affect its materiality could induce, its 1996 reintegration into Sarajevo (i.e. in the Federation), as stipulated by the Dayton Agreement, relocated Grbavica in the horizon of bodily movement of most Sarajevans, and relegated it to an affective no-go area for some East Sarajevans. Trebević, on the other hand, is now mainly on East Sarajevo territory. Many still associated Grbavica with horrific war-time events, but affect related to post-war political border-drawing turns out to explain more than war-related affect induced by the materiality of particular things. Had the Dayton negotiators drawn this line elsewhere, bodily practice would probably have shaped up accordingly, as we did indeed find with successive population movements following border shifts. If we are alert to changes in people's practices over time, we thus find that the IEBL could overrule the affective 'charge' of things.

As in my genealogy, I find that to state that the purification between human and nonhuman actants is 'spurious' would not improve this account. A key reason is straightforwardly methodological: what would certainly be spurious-as in: unsupported by my ethnographic research-would be arguments to the affect that certain things 'exuded' certain affects. My account of the affective dynamics in asymmetrical comings and goings that materialised the Dobrinja border is grounded in observation and in communication. This communication unfolded between people and myself and was often about things, but clearly I could not claim to have had the same kind of communication with things. To flatten 
this distinction through attributions of certain agencies to things would render my account unaccountable, because my ethnographic methodology cannot support them in ways that are disputable by others.

When people from 'Federal' Dobrinja are more likely to visit Grbavica than Trebević, we should further understand that this is only partly due to affective dynamics of things or IEBL drawing. Grbavica is an urban quarter offering many services, and the trolleybus from Dobrinja to the city centre runs through it. Trebević, on the other hand, is a forested mountain, before the war served by cable way, now without city transport. This leads us back to the materiality of these things and to the way in which borderwork unfolds on the intersection of different scales. To delve into this prosaic yet crucial dimension of bodily movement away from the border, let's walk through our street again.

\section{Two centripetal patterns of movement}

On the west side of our street we find a gas pipe box. This thing is labelled Sarajevogas after the public company that delivers gas to all of Sarajevo up to the west side of the street, but no further. This box-and the network it is part of-embodies the border in residents' lives through practices of public provision, i.e. as part of government. People living on the east side of our street are subject to government by the municipality of East Sarajevo and RS, and those on the west side to those of the municipality of New Town Sarajevo, Canton Sarajevo, and the Federation. Regardless of affect, then, their residence on one side of the street determines whether they should turn their pipes east or west to have gas delivered. The same is true for most administrative procedures, welfare provision, police protection, public health care, taxes, judicial services, etc. ${ }^{9}$ Bills or complaints carried to relevant offices require bodily movement away from the border. Yet this can in fact be affectively oblivious to that border: it is centripetal movement towards locations where government and provision are managed.

Of course all inhabitants of our street are also subject to some practices of sovereignty by $\mathrm{BiH}$, but the bulk of administrative and provisioning encompassment is organised (or, as many complain, disorganised) on the Entity, Canton or municipality level. In terms of 'government', then, our street residentially demarcates two different 'populations' (Foucault 1991) converging around different things. And this has far-going performative bordering effects. A methodological focus on things thus alerts us to the everyday practical structuring of bodily movement through government and urban logistics as perhaps the most powerful dimension of the materialisation of the border. Before we ask why most people didn't cross, we must acknowledge that, on the whole, they didn't need to. A more relevant question is: why would they cross?

This practical dimension is also important to a further pattern. If we sit long enough at the end of our street, we notice the density of (non-)crossing is actually asymmetrical. On working day mornings, most human traffic is from east to west, and in late afternoons from west to east. Another such back-and-forth wave occurs on evenings, especially during weekends. On aggregate, then, people from East Sarajevo cross the border more frequently. ${ }^{10}$ This is counter-intuitive when considered in the light of the politics of the IEBL. My genealogy showed how self-encapsulated administration and provision, and the creation of two populations, was not sought symmetrically by 'two sides', with a border-as-line then 
demarcating them. Instead, the border was produced by the making of East Sarajevo and RS as exclusively Serbian units.

We thus find that those most committed to this border-East Sarajevans-crossed it most frequently. And those who denied it legitimacy 'respected' it most in bodily practice. A focus on war-related affect 'exuded' by things cannot explain this. It would lead us to expect the reverse. Yet a methodological zoom on things does prove useful, alerting us to how human practices congeal around things in contradictory patterns on different scales. When East Sarajevans crossed the border, their destination was generally in or around the city centre, where they attended to administrative issues (e.g. in state institutions or embassies), consumption and leisure (more choice) or family visits. Importantly, many East Sarajevans were employed in Sarajevo, which had a much larger labour market with more attractive opportunities. While on the Sarajevo 'open' labour market people from East Sarajevo were even more unlikely to find jobs than others, many found employment through quotas in $\mathrm{BiH}$ state institutions and foreign organisations. People from 'Federal' Dobrinja also commuted to the centre, often for similar reasons, but this did not involve any border-crossing. Their much less frequent turns eastwards, into East Sarajevo, allowed savings on certain purchases (e.g. petrol) or stop-overs in transit. Some went there for the larger choice of pork sausages. Hence, in effect, zooming in on things shifts our attention from war-related affect to more banal practices. Sarajevans usually had no reason to go to East Sarajevo, just like people elsewhere may rarely enter new, further outlying and badly connected areas. To a large degree, the asymmetry in aggregate bodily movement was thus due to a second centripetal pattern, relatively oblivious of the border itself: the logistics of suburban residence.

Integrated in an analysis of regularities of bodily movement, then, a focus on things, on configurations of gas pipes and trolley bus lines, on the circulation of money, gas and pork sausages, is methodologically useful to describe the materialisation of the border through movement away from it and through asymmetric crossings. It also has particular critical value concerning the question how much of a border materialises in the process, for whom, and on which scale, reminding us that not all practices that reproduce borders are experienced as border-salient by those engaged in them. Bodily movement is mostly subject to practical concerns: if people go somewhere, it is to do something. We should therefore not expect that (non-)crossing this border automatically implies (non-)transgression of wartime divisions. This tendency to assume that every single engagement with borders must mean something in terms of its legitimacy is a problem in reconciliation discourse which attributes moral superiority to cross-border communication simply because it is crossborder, and thereby reproduces the grammar of discrete 'sides' (Jansen 2010). Likewise, many border studies pay an extraordinary amount of attention to the transgression of borders, treated as metaphors for modernity-more precisely, for its classificatory drive, seen as the key logic underlying sexist, nationalist, racist and other forms of oppression. While critical of the notion of borders-as-lines, their celebrations of transgression as 'resistance' paradoxically reinforce the line-like hegemonising power of borders. In contrast, a focus on things alerted us that much bodily movement around our border can be understood through a double centripetal logic of the practical suburban workings of government, provision, employment and consumption. Clearly, no analysis of the IEBL can ignore its affective significance, but a methodological zoom on how human practices shape up around things on different scales shows that much bodily movement that is more or less oblivious to such affect nevertheless materialises this border. 


\section{Concluding remarks}

Most border studies foreground reification, and their analysis of borderwork thus uses different analytical registers of agency for people and for things. Thingism rejects this distinction as spurious. Where does an ethnographic account of borders turn at this fork? Debates around thingism usually revolve around questions of the nature of agency and specifically around the role of intentions-opponents argue that the intentions of human actants should lead us to distinguish them from non-human actants, and proponents object to such assumptions of asymmetry. Instead, my argument is grounded in a concern with accountability. This allows for privileging people's intentions but, as I show, it does not necessarily have to imply that. My article thus charts the (re)production of a Sarajevo border over time and on different scales through regularities in infrastructural dynamics of wartime and post-war polity-making, affect and bodily movement. I found that a focus on things that stops short of a thingist approach provided the best descriptive account of this border as well as the greatest critical potential. Let me recapitulate:

First, my genealogical description included people and things, yet did not collapse them into one analytical category. I found there simply was no good reason to do so, whereas there were good reasons to distinguish between them. Human practices could not be understood without tracing how they congealed around things (mines, barricades, a flight simulator), but ultimately none of these particular things were necessary conditions in the making of this border, while human borderwork was. True to this, my account thus needed to explain how the border was, above all, a contingent product of human practice through things. The accounts of Dobrinja residents, even those with strong political commitments to this border's legitimacy, did not pretend otherwise. Nor did my ethnographic description, for which I can be held accountable by those residents and by (other) readers. Such an accountable account of how a street became a border would not gain anything from an insistence on the a priori equivalence of the agency non-human and human actants. A methodology that worked through things proved to be useful, but any genealogical account of this border would have arrived at a point where human agency emerged-at least a posteriori-as categorically different from non-human agency. If those forms of agency were not equivalent, using equivalent verbs for them would needlessly confuse and blur our account. To understand the genesis of this border, a focus on things worked best insofar as it allowed a more precise tracing of the reification of the border on different scales as a process over time.

Second, to understand how a Dobrinja street became a border in particular ways, with more or less intensity, for particular people, on particular scales, I included an account of dynamics of affect. Here, I 'purified' human from non-human actants on methodological grounds. Based on observation and conversation, my research allowed me to make an accountable claim that certain people projected certain forms of affect onto certain things, but I cannot make an equivalent ethnographic argument in support of the statement that 'things exude affect' because I have no equivalent ethnographic methodology. Again, this is not a matter of privileging human intentions per se. Our analysis might include them, and, depending on our objectives, this may sometimes be preferable, but my case study did not need to centre on them. I purified because my ethnographic methodology allowed me to build an accountable account that included insights on how people experienced, directed 
and understood some of their practices-important ones for our understanding of this border-as goal-oriented, meaningful and affectively loaded. To reflect this I used nonequivalent verbs for non-equivalent actants.

Third, I favoured de-reification over de-purification to maximise the critical potential of my ethnography. Rejecting the liberating aspirations of Enlightenment-inspired critical social science, many thingists formulate their own strident claims of emancipatory promise, both in terms of knowledge production (e.g. overcoming the subject-object distinction) and in terms of a politics of freedom (e.g. Latour's 'republic of people and things' (2005b) or Viveiros de Castro's 'ontological self-determination for peoples' (2003)). De-purification, i.e. reinstating non-human actants to their rightful status, may indeed open up better planetary co-existence, and such recognition may be emancipatory for people whose ontologies are suppressed by dominant anthropocentrism. Yet in their rush to state such critiques (often in the name of others, less prone to purification than an anthropology tainted by 'modernist hubris'), thingists lose sight of the critical potential of de-reification. An ethnographer confronted with nationalist proclamations of all kinds of things as ontologically national, with a street that functions as an actant in a suddenly, violently formed bordering actor network, could decide to embrace this as de-purification and let it lead the analysis. To allow critical reflection on the burning issue of accountability in the division of Sarajevoand to make my own account accountable-I chose de-reification as the more promising track.

Fourth, a strong methodological focus on things did prove effective in ways unforeseen by thingism. In many ways, this border could be said to have emerged 'out of nothing': it is an example of radical contingency at work. Yet where a conventional dereifying approach in border studies might have stopped there, a thing-centred methodology uncovered how this border actually emerged, as it were, out of 'many things'. Stopping short of thingist treatment of people and things as actants of the same order, a systematic focus on things-on buses, pork sausages, gas pipes-proved to be useful to prevent an overemphasis on meaning, representation and, of course, intention. Charting how our border materialised through human practices that congealed around things over time, I uncovered a double pattern of centripetal governmental and suburban logistics, relatively oblivious to the affective significance of asymmetrical (non-)crossing, as a key dimension in the materialisation of our border. A focus on things thus became useful not in the way suggested by thingism-de-purifying, highlighting the equivalent agency of things-but insofar as it helped further and more sophisticated de-reification of the border. A multiscaled thing-led methodology became a central plank of my accountable account of the reification of this border, tracing the contingent practices by (ultimately, in principle, accountable) people that do the reifying from Dobrinja to Dayton and back again.

\section{Acknowledgments}

Thank you to the people who agreed to participate in this research; to Jelena Ostojić, Melina Sadiković and Mirjana Ostojić for research assistance; to the Leverhulme Trust and the British Academy for financial support; and to Čarna Brković, Nejra Nuna Čengić, Soumhya Venkatesan, Vanja Čelebičić, SA/AS reviewers and editors for constructive criticism. 


\section{List of references}

C-Lab. n.d. 'Richard Holbrooke, arhitect' C-Lab 13, 138-143. [c-lab.columbia.edu/ holbrooke.html, accessed May 2012)

Foucault M. 1991. 'Governmentality' In: Burchell G., Gordon C. \& Miller P. (eds) The Foucault effect: studies in governmentality. London: Harvester Wheatsheaf. 73-86.

Green S. 2009. 'Lines, traces and tidemarks: reflections on forms of borderli-ness' Working Paper 1 (WG1), COST ESF ISO803 Network Remaking Eastern Borders.

Henare A., Holbraad M. \& Wastell S. (eds) 2007. Thinking through things: theorising artefacts ethnographically. London: Routledge.

Ingold T. 2000. The perception of the environment: essays on livelihood, dwelling and skill. London: Routledge.

Jansen S. 2010. 'Of wolves and men: postwar reconciliation and the gender of inter-national encounters' Focaal: Journal of Global and Historical Anthropology 57: 33-49.

Latour B. 2005a. Reassembling the social: an introduction to actor-network theory. Oxford: Oxford UP.

Latour B. 2005b. 'From Realpolitik to Dingpolitik: or how to make things public' In: Latour B. \& Weibel P. (eds) Making things public: atmospheres in democracy. Cambridge: MIT Press.

Massey D. 2005. For Space. London: Sage.

Miller D. 2006. Materiality. Durham: Duke UP.

Navaro-Yashin Y. 2009. 'Affective spaces, melancholic objects: ruination and the production of anthropological knowledge' Journal of the Royal Anthropological Institute 15(1): 1-18.

Thrift N. 2008. Non-representational theory: space/politics/affect. London: Routledge.

Venkatesan S. 2009. 'Rethinking agency: persons and things in the heterotopia of "traditional Indian craft"' Journal of the Royal Anthropological Institute 15(1): 78-95.

Viveiros de Castro E. 2003. And. Manchester Papers in Social Anthropology 7.

\footnotetext{
${ }^{1}$ On the main roads around Dobrinja asymmetrical sets of 'welcome' and 'goodbye' signs have appeared over the years but in 2008-10 there were none in residential areas, where most pedestrian traffic and city passenger transport occurs.

${ }^{2}$ Since 1993, 'Bosniak' has overtaken 'Bosnian Muslim' as a self-identifying and official label for Bosnians with Islamic socioreligious heritage.

${ }^{3}$ Establishing RS, Serbian nationalist elites sought to prevent the independence of BiH within its Yugoslav republican borders, to nationally homogenise and separate the $\mathrm{BiH}$ population, and to establish Serbian domination on all or most of BiH territory.

${ }^{4}$ Due to additional evacuations, many buildings were in fact not inhabited until 1994.

${ }^{5}$ Figures depend on territory included and are unreliable since no census was held in BiH since 1991.

${ }^{6}$ Note that the street sign on the west makes reference to a 'Bosnian Assembly', not to something Bosniak. This reflects the ambiguous political symbiosis between inclusive pro-BiH and exclusive pro-Bosniak discourse.

${ }^{7}$ Some coaches leaving from East Sarajevo turn west, but their final destination lies outside Sarajevo.

${ }^{8}$ Note that most people from RS or the Federation cannot be distinguished on sight, especially after the 1998 foreign-imposed introduction of uniform BiH licence plates.

${ }^{9}$ There is one exception: running water to both sides of the street is delivered from RS. Again, a focus on things in human practice helps us explain this: after the war, the pre-war underground pipe network was restored into function.

${ }^{10}$ In an important exception, many Serbian parents resident in 'Federal' Dobrinja, especially from returnee families and in the 're-integrated' sections, prefer the 'Serbian' curriculum to the 'Federal' one, and send their children to school in RS.
} 